\title{
Base Nacional de Serviços Públicos do Brasil: sistematização e interoperabilidade de informações para o Governo Digital
}

\author{
National Base for Public Services in Brazil: systematization and interoperability of \\ information for Digital Government
}

\author{
Thiago José Tavares Ávila ${ }^{1}$, Beatriz Barreto Brasileiro Lanza ${ }^{2,3}$, Daniel de Souza Valotto ${ }^{3}$ \\ ${ }^{1}$ Fundação Getúlio Vargas, São Paulo, Brasil. \\ ${ }^{2}$ State University of New York, New York, USA. \\ ${ }^{3}$ Universidade Federal do Paraná, Paraná, Brasil.
}

\section{N F O A R T I GO}

\section{Palavras-chave:}

Base Nacional de Serviços

Públicos do Brasil,

Interoperabilidade,

Governo Digital,

Estados.

\begin{abstract}
RESUMO
Com os avanços do Governo Digital no Brasil, bem como o enforcement trazido pela Lei Federal 13.460/2017 quanto a criação das Cartas de Serviços ao Usuário, de um lado, ampliou-se a oferta de informações sobre serviços públicos, por outro lado, essa oferta encontra-se dispersa em diversas plataformas e portais de serviços. Neste sentido, a Lei Federal 14.129/2021 instituiu a Base Nacional de Serviços Públicos visando sistematizar tais informações, mas sem especificar como esta Base pode ser estruturada de forma prática. Por meio de uma análise transversal de dados secundários, $o$ presente artigo buscou-se sistematizar o status de oferta de informações sobre serviços públicos no Brasil, nos portais estaduais e federal, identificando os componentes para a Base Nacional de Serviços Públicos. A pesquisa evidencia a complexidade dessa oferta de informações, bem como propõe os componentes mínimos para a estruturação da Base Nacional de Serviços Públicos, discutindo os principais desafios para a sua consolidação no contexto brasileiro.

A B S T R A C T
\end{abstract}

The advances of the Digital Government in Brazil, as well as the enforcement brought by Federal Law 13,460/2017 regarding the creation of User Service Charters, on the one hand, expanded the offer of information on public services. On the other hand, this offer is spread across several platforms and service portals. In this sense, Federal Law 14.129/2021 established the National Base for Public Services aiming to systematize such information, but without specifying how this Base can be structured. Through a cross-sectional analysis of secondary data, this paper tried to systematize the status of information on public services in Brazil, specifically in states and federal portals, identifying the components for the National Public Services Base. The research results highlight the complexity of this information offer, as well as proposes the minimum components for the structuring of the National Public Services Base, discussing the main challenges for its consolidation in Brazilian context. 


\author{
Correspondência para autores: \\ thiago.avila@fgv.edu.br (Ávila, T.J.T.) (ORCID: 0000-0003-4042-2243), \\ beatrizlanza@gmail.com (Lanza, B.B.B.) (ORCID: 0000-0001-6388-0429), \\ danielvaloto@gmail.com (Valotto, D.S.) (ORCID: 0000-0001-6381-7809).
}

\title{
1. Introdução
}

As constantes mudanças econômicas, políticas, sociais e tecnológicas, aliadas a orçamentos restritos e expectativas crescentes dos cidadãos tornam imperativa a transformação digital no setor público (CAVALCANTE; CAMÕES, 2017). Nesse cenário emergem novos desafios e oportunidades para os governos (MEYERHOFF; NIELSEN; JORDANOSKI, 2020) e novos modelos de relacionamento entre governos e cidadãos (CUNHA; MIRANDA, 2013).

Nessa nova maneira de gestão onde os governos estão procurando maneiras de se tornar mais eficientes, eficazes e coordenados, as tecnologias da informação e comunicação (TIC) tornaram-se um componente importante. Cada vez mais, agências governamentais estão explorando tecnologias emergentes para ajudar a melhorar suas operações internas e seus relacionamentos com cidadãos e outros atores sociais.

O Governo Digital vem ganhando protagonismo na agenda de políticas públicas dos entes federados brasileiros desde os anos 2000. Atos normativos relacionados ao Governo Digital e à simplificação do relacionamento Estado-sociedade foram sancionados, como as Leis Federais 12.527/2011, 13.460/2017 e 14.129/2021, conhecidas respectivamente como "Lei de Acesso à Informação - LAI", "Código de Defesa do Usuário do Serviço Público - CDU” e "Lei do Governo Digital e da Eficiência Pública - LGD” (BRASIL, 2011, 2017 e 2021a).

A partir dessas normativas, especialmente do conjunto de obrigações trazidas pelos Art. $3^{\circ}$ a $7^{\circ}$ do CDU, os Poderes Públicos e respectivas instituições tornaram-se obrigados a: catalogar e disponibilizar a sua oferta de serviços públicos ao usuário e; aplicar soluções tecnológicas que visem a simplificar processos e procedimentos de atendimento ao usuário e a propiciar melhores condições para o compartilhamento das informações.

Considerando esta ampla catalogação, está sendo construído um grande volume de informações sobre serviços públicos decorrentes em especial, do enforcement causado pela legislação recente. Tais informações estão dispersas em múltiplas e diferentes plataformas digitais, impondo assim barreiras e dificuldades ao cidadão quanto ao acesso às informações e aos serviços, de forma simplificada e conforme os fundamentos do Governo Digital.

Nesta direção, a Lei 14.129/2021 - “Lei do Governo Digital e da Eficiência Pública - LGD” - prevê a criação de uma Base Nacional de Serviços Públicos (BRASIL, 2021a) que "reunirá informações necessárias sobre a oferta de serviços públicos em cada ente federado". Segundo o Art. 18 desta lei, "cada ente federado poderá disponibilizar as informações sobre a prestação de serviços públicos, conforme disposto nas suas Cartas de Serviços ao Usuário, na Base Nacional de Serviços Públicos, em formato aberto e interoperável [...]" (BRASIL, 2021).

Dado que a LGD ainda carece de maiores compreensões, este trabalho visa sistematizar o a oferta de informações sobre serviços públicos no Brasil nos portais estaduais e federal, identificando características e 
requisitos para a Base Nacional de Serviços Públicos no Brasil. Além desta introdução, o estudo possui uma revisão de literatura, os procedimentos metodológicos, resultados, e por fim, as considerações finais e limitações da pesquisa.

\section{Referencial Teórico}

\subsection{Modernização da Administração Pública e Governo Digital}

As tecnologias e os serviços digitais podem servir como catalisadores para melhorar as vidas dos cidadãos, impulsionar a produtividade e a criação de emprego, emancipar minorias e reforçar a governança democrática e a transparência. Com esse potencial, a Transformação Digital (TD) no setor público tornou-se rapidamente o principal objetivo dos governos de países desenvolvidos e em desenvolvimento (BANCO MUNDIAL, 2016; COMISSÃO EUROPEIA, 2017). Países em todos os níveis de desenvolvimento exploram os benefícios das tecnologias digitais para promover ou melhorar o desempenho do setor público e a qualidade dos serviços, contribuindo para o aumento da confiança dos cidadãos nos governos (OCDE, 2018).

$\mathrm{O}$ incremento da adoção de tecnologias digitais para aprimorar o relacionamento entre governo e sociedade tem sido uma realidade ao longo das últimas duas décadas no Brasil e no mundo. Tal fenômeno pode ser compreendido como Governo Digital e sobre este conceito, podemos compreender a visão de diversos autores.

O Governo Digital pode ser entendido por entidades públicas que adotam tecnologias digitais como uma parte integrada das estratégias de modernização de seus governos para criar valor público OCDE (2014); ou o.uso de TICs pelo governo, como a oferta de serviços online, vem sendo um aspecto essencial da inovação, coprodução, transparência e geração de valor público (GIL-GARCIA; DAWES e PARDO, 2017).

Segundo Gil-Garcia (2012), no âmbito de um Governo Digital, a maioria dos desafios não está relacionado à tecnologia, onde a integração de informações do governo pode continuar a ser um problema complexo devido à dificuldade de mudar as características das organizações governamentais, incluindo sua natureza altamente política. Os desafios passam por mudanças na estrutura dos silos do governo, arranjos institucionais e cultura organizacional difundida, que juntos limitam os incentivos para colaboração e compartilhamento de informações.

No Brasil, a estratégia de construção de um governo digital teve início na década de 2000 (FILGUEIRAS; FLÁVIO; PALLOTI, 2019), onde a legislação para suportá-lo foi sendo estruturado desde então. Em consonância com os objetivos desta pesquisa, três marcos merecem destaque: (1) A Lei 12.527/2011, conhecida como Lei de Acesso à Informação - LAI; (2) A Lei 13.460/2017, conhecida como Código de Defesa do Usuário do Serviço Público - CDU e; (3) a Lei 14.129/2021, conhecida como Lei do Governo Digital e da Eficiência Pública - LGD. Tais leis abordam os principais conceitos e fundamentos para o Governo Digital, especialmente assuntos ligados à melhoria da oferta de serviços públicos e a integração e interoperabilidade de processos e informações governamentais necessários para esta oferta.

Numa visão temporal, estas três leis criaram a estrutura normativa necessária para os fundamentos do Governo Digital bem como para a concepção de uma Base Nacional de Serviços Públicos. Inicialmente, a LAI, no seu Art. $8^{\circ}$ instituiu a obrigação de entidades públicas divulgarem informações próprias que sejam de interesse coletivo, devendo estes utilizarem sítios oficiais na internet de forma que possibilitem acesso 
automatizado por sistemas externos, estruturados e legíveis por máquina (BRASIL, 2011).

Numa segunda etapa, o CDU instituiu, para toda a administração pública brasileira, nos seus Arts. $3^{\circ}$ e $7^{\circ}$ respectivamente, os conceitos do Quadro Geral de Serviços Públicos, "que especifica os órgãos ou entidades responsáveis pela realização dos serviços e a autoridade administrativa a quem estão subordinados ou vinculados"; e das Cartas de Serviço ao Usuário que tem por objetivo "informar o usuário sobre os serviços prestados pelo órgão ou entidade, as formas de acesso a esses serviços e seus compromissos e padrões de qualidade de atendimento ao público" (BRASIL, 2017). Por fim, a LGD, no seu Art. 18, apresenta como componentes do Governo Digital a Base Nacional de Serviços Públicos - BNSP, as Cartas de Serviço ao Usuário e as Plataformas de Governo Digital.

Diante deste desafio complexo de estruturar o Governo Digital em um país como o Brasil, ressaltase as instâncias institucionais de articulação e convergência da agenda de Governo Digital. Em 2020 foi instituída a Rede Nacional de Governo Digital - Rede Gov.br, de natureza colaborativa e adesão voluntária, no âmbito da União, dos Estados, do Distrito Federal e dos Municípios, com a finalidade de promover o intercâmbio de informações, contando com 14 estados e 35 municípios (BRASIL, 2021c).

Em 2019, foi criado o Grupo de Transformação Digital dos Estados e do Distrito Federal GTD.GOV. O Grupo, que é a primeira iniciativa brasileira que concatena esforços de Transformação Digital (TD) na esfera estadual de governo, tem a missão de acelerar a TD dos serviços públicos nos 27 Governos estaduais do Brasil (ARAÚJO; ÁVILA; LANZA, 2021).

\subsection{Integração e Interoperabilidade de dados e informações para o Governo Digital}

Segundo Camboim (2013), a crescente disponibilidade de dados da web criou uma perspectiva para que essa oferta de dados se estruture como única base interligada de conhecimento a ser explorada, onde os governos, como grandes produtores de informação essencial, também estão sendo exigidos para que a publique de forma aberta, transparente $\mathrm{e}$

processável por máquina. A expansão na quantidade de bases de dados conectadas globalmente caracteriza a existência da "web de dados", definida como "uma rede de coisas do mundo físico descritas por dados na web" (BIZER; HEATH; BERNERS-LEE, 2009).

Os governos sempre foram grandes produtores e consumidores de dados, seja por conta de seus procedimentos de rotina ou por determinação legal (CAMBOIM, 2013). Vários autores exploram o desafio que governos enfrentam quanto a falta de integração e interoperabilidade de dados e informações. Batista, Silva e Miranda (2013) apontam que os dados governamentais são armazenados em silos isolados e que com o passar dos anos, o volume de dados tem crescido, onde a falta de interoperabilidade entre diferentes instituições torna-se mais crítica, onde o desafio não é apenas tecnológico, mas como as informações são tratadas e organizadas.

Para a integração de informações de governo, os benefícios técnicos também podem ser representados pelo desenvolvimento de arquiteturas e infraestruturas técnicas comuns. No geral, os benefícios técnicos podem ajudar a fornecer melhores sistemas de informação para diversas partes interessadas, incluindo agências governamentais, cidadãos, empresas e organizações sem fins lucrativos (GIL-GARCIA, 2012).

A integração de processos, o compartilhamento de informações e a interoperação de sistemas de 
informação no governo são fenômenos intimamente interligados que expõem altos graus de complexidade (SCHOLL; KLISCHEWSKI, 2007). Quanto maior o grau de integração e interoperação melhor a orientação para o serviço e a flexibilidade no governo (KLIEVINK; JANSSEN, 2009). Todavia, a maioria dos esforços de integração e interoperação são desafios e limitações para a efetividade do e-governo (GOTTSCHALK, 2008).

A resolução de problemas de interoperabilidade passa pelo estabelecimento de padrões e uniformização dos meios e mensagens trocadas pelos sistemas e instituições (BATISTA; SILVA; MIRANDA, 2013). Tais padrões de interoperabilidade demandam a articulação de outros fatores para o compartilhamento de informações, como políticas, recursos humanos e tecnologias da informação apropriadas. Nessa direção, as Infraestruturas de Dados (IDs) apresentam-se como soluções para a integração, interoperabilidade e organização de grandes bases de dados de interesse comum (ARIZA, 2002; CAMBOIM, 2013).

As Infraestruturas de Dados Espaciais (IDEs) são o conjunto de tecnologias, políticas públicas e arranjos institucionais para facilitar a disponibilização e o acesso a dados espaciais, com a finalidade de harmonizar e distribuir informações de maneira interoperável (NEBERT, 2004; MARANHÃO, 2013), sendo formadas, da união de usuários, produtores e reguladores do uso de geoinformação (CAMBOIM, 2013).

O principal benefício de uma IDE é essencialmente prover as condições para a coordenação, integração, troca e partilha de dados geográficos entre diferentes atores de vários níveis da comunidade de dados espaciais. As IDEs assumem uma grande importância no contexto da gestão de informação espacial para a tomada de decisões, como forma de garantir um desenvolvimento economicamente e ambientalmente equilibrado (LIMA, 2012)

Para as IDs, Maranhão (2013, apud Nakamura, 2010) apontam que seus componentes são as pessoas, dados, redes, políticas de acesso e os dados, apontando a existência de uma estrutura hierárquica entre as infraestruturas de dados, classificando-as desde um nível global até um nível local, conforme a Figura 1. Rajabifard et al. (2000) expande as características básicas das IDs incluindo conjuntos de dados fundamentais, escalas, normas técnicas, redes, pessoas, coordenação e fatores de influências externas.

Figura 1 - Hierarquia das Infraestruturas de Dados.

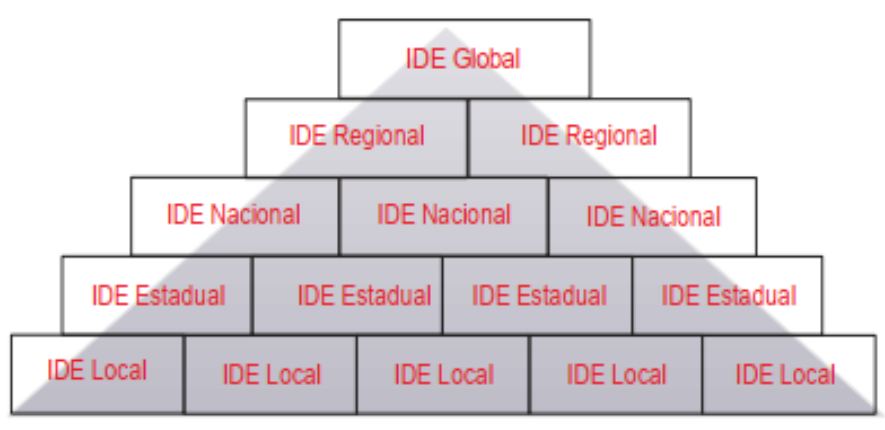

Fonte: Nakamura (2010).

No contexto brasileiro, o Decreto Federal $n^{\circ}$ 6.666, de 27 de novembro de 2008 criou a Infraestrutura Nacional de Dados Espaciais - INDE-BR, com o objetivo de estruturar o ciclo de produção, compartilhamento 
e disseminação de dados espaciais no Brasil, promovendo a produção e utilização desses dados pelas instituições públicas (adaptado de BRASIL, 2008). A INDE possui dois componentes relevantes que são o Diretório Brasileiro de Dados Geoespaciais - DBDG e o Portal Brasileiro de Dados Geoespaciais.

Como uma evolução da INDE-BR, em 2011 foi concebida a Infraestrutura Nacional de Dados Abertos (INDA) - que é um conjunto de políticas e de meios para catalisar a publicação e o acesso a dados abertos do governo, onde o Portal Brasileiro de Dados Abertos (dados.gov.br) é o seu principal meio de acesso (BATISTA; SILVA; MIRANDA, 2013).

Por outro lado, considerando a análise temporal de comandos estabelecidos pelas Leis 12.527/2011 (informações de interesse geral em formato aberto), 13.460/2017 (cartas de serviços ao usuário para todos os órgãos e entidades da administração pública) e 14.129/2021 (Base Nacional de Serviços Públicos, reunindo as informações das Cartas de Serviços ao Usuário de todas as instituições públicas), podemos verificar a existência de características pertinentes as IDs como meios de organização estruturada dessas informações sobre serviços públicos, em consonância com as diretrizes apresentadas por Maranhão (2013), Nakamura (2010) e Rajabifard et al. (2000).

\subsection{Componentes do Governo Digital do Brasil}

\subsubsection{Cartas de Serviços ao Usuário}

As Cartas de Serviço ao Usuário podem ser definidas como "um documento elaborado por uma organização pública que visa informar aos cidadãos quais são os serviços prestados por ela, como acessar e obter esses serviços e quais os compromissos de atendimento estabelecidos", podendo também ser entendidas como "um compromisso da Administração Pública para com a cidadania" (CRESPO; GONZÁLEZ; CRIADO, 2005; STOECKL; STOECKL, 2017).

O CDU estabelece que "a Carta de Serviços ao Usuário deverá trazer informações claras e precisas em relação a cada um dos serviços prestados” (BRASIL, 2017). A legislação ainda detalha o conteúdo mínimo a ser apresentado pela Cartas de Serviços.

Conforme o CDU, o Quadro Geral dos Serviços Públicos prestados, específica os órgãos ou entidades responsáveis por sua realização e a autoridade administrativa a quem estão subordinados ou vinculados, sendo composto pelo conteúdo das Cartas de Serviços ao Usuário. Ambos são uma obrigação legal para todos os órgãos da administração pública brasileira conforme estabelecido pelo Art. $1, \S 1^{\circ}$ do $\mathrm{CDU}$, devendo sua operacionalização ser regulamentada por cada Poder e esfera de Governo (BRASIL, 2017).

\subsubsection{Base Nacional de Serviços Públicos - BNSP}

De acordo com a LGD, a BNSP consiste em uma base de dados que contém as informações necessárias sobre a oferta de serviços públicos de todos os prestadores desses serviços. Neste sentido, a LGD, no seu Art. 54 alterou o CDU, instituindo um comando que vincula as Cartas de Serviços ao Usuário com a Base Nacional de Serviços, estabelecendo que compete aos entes federados disponibilizas as informações dos serviços prestados em formato aberto e interoperável (BRASIL, 2021).

O artigo 19 da LGD descreve que "poderá o Poder Executivo federal estabelecer Base Nacional de Serviços Públicos, que reunirá informações necessárias sobre a oferta de serviços públicos em cada ente 
federado" e que "cada ente federado poderá disponibilizar as informações sobre a prestação de serviços públicos, conforme disposto nas suas Cartas de Serviços ao Usuário, na Base Nacional de Serviços Públicos, em formato aberto e interoperável e em padrão comum a todos os entes".

Em analogia com o modelo federativo do Brasil, estruturado na União, Estados e Municípios, observa-se uma lógica hierárquica na organização de tais informações, estando em consonância com as diretrizes apontadas por Maranhão (2013, apud Nakamura, 2010).

Quanto a necessidade da estruturação da BNSP, Alagoas (2018) aponta que está sendo construído um grande volume de informações sobre serviços públicos, decorrentes das Cartas de Serviços ao Usuário dos entes federados. Contudo, tais informações estão dispersas em diversas plataformas digitais, impondo barreiras para o cidadão acessar os serviços de forma simplificada conforme preconizado pelo Governo Digital. Por outro lado, com a BNSP, cria-se uma janela de oportunidade para a melhoria de serviços públicos, em escala nacional, através da comparação entre serviços públicos similares prestados por entes federados distintos e respectivas boas práticas implantadas para os serviços.

O modelo inicial da BNSP, que está documentado em Alagoas (2018), estabeleceu premissas para que os entes federados possam aderir a BNSP como: (i) haver coordenação institucional e técnica sobre a oferta de serviços públicos do ente federado; (ii) o portal/plataforma de serviços estaduais disponibilizar um conjunto mínimo de informações sobre os serviços públicos em formatos abertos e processáveis por máquina, através do desenvolvimento de interfaces de programação (APIs), conforme a Figura 2.

Figura 2 - Esquema conceitual de compartilhamento de informações para a BNSP.

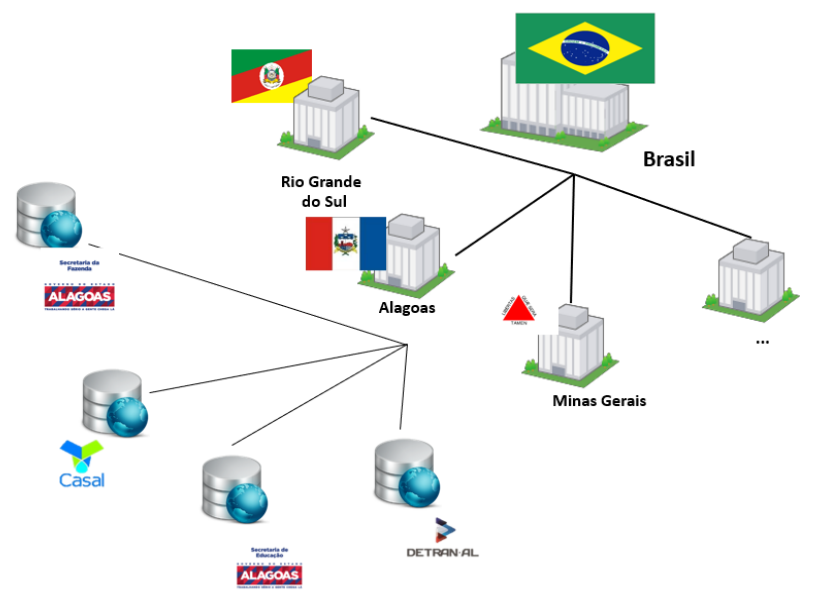

Fonte: ALAGOAS (2018).

No presente momento, o Portal gov.br (BRASIL, 2011e) é o principal repositório de informações sobre serviços públicos em alinhamento com o conceito da BNSP, pois disponibiliza informações sobre serviços federais e de oito governos estaduais.

\subsubsection{Plataformas de Governo Digital}

Como um dos componentes do Governo Digital brasileiro, as plataformas de governo digital consistem em ferramentas digitais e serviços comuns aos órgãos, normalmente ofertados de forma 
centralizada e compartilhada, necessárias para a oferta digital de serviços e de políticas públicas (BRASIL, 2021). Srnicek (2017) pondera que as plataformas atuam como infraestruturas digitais que permitem que parceiros interajam, produzindo efeitos de rede, ou seja, quanto mais usuários, mais valiosa ela se torna para todos os que fazem parte da rede. Pensar o governo enquanto plataforma pode significar mais serviços integrados, menor custo para o governo e para os usuários (ARAÚJO; ÁVILA; LANZA, 2021).

Segundo Gonçalves e Ricciardi (2016) os portais e plataformas de serviços atuam como uma carta de serviços "viva", "em tempo real", em alinhamento com os comandos do CDU, onde a Carta de Serviços ao Usuário será "objeto de atualização periódica e de permanente divulgação mediante publicação em sítio eletrônico do órgão ou entidade na internet”. Mezzaroba et al. (2016) complementa que os portais eletrônicos, plataformas online que oferecem serviços e informações aos cidadãos de maneira fácil, relevante e efetiva, são considerados uma importante ferramenta de interação com a população

Em 2015 foi lançado no Brasil o Portal de Serviços Públicos do Governo Federal, que passou a reunir diversos serviços públicos de maneira digital, com uma busca facilitada, linguagem acessível a toda a população e foco na experiência do usuário do serviço (FILGUEIRAS; FLÁVIO; PALOTTI, 2019). A partir de 2019, surge o portal gov.br objetivando reunir em um único endereço todas as páginas e serviços oferecidos pelo Poder Executivo Federal (BRASIL, 2015). O gov.br já conta com mais de 106 milhões de usuários, reúne mais de 4 mil serviços públicos de cerca de 200 órgãos de governo e pretende até o fim de 2022 oferecer mais de 3000 serviços totalmente digitais, o que pode gerar uma economia aos cofres públicos de até R\$ 38 bilhões até 2025 (BRASIL, 2021b).

Todavia, ainda que na esfera federal o Brasil detenha uma postura proeminente com seu PSC, nas esferas estaduais e municipais não se percebe a mesma força. Por ser um país de dimensões continentais, com oito milhões de quilômetros quadrados, mais de 200 milhões de habitantes, espalhados em 26 estados, um Distrito Federal e em 5.570 municípios (IBGE, 2018ab), os governos de esferas subnacionais enfrentam diferenças regionais de ordem política e socioeconômica, além de diversos entraves burocráticos (MACIEL; PIZA; PENOFF, 2009).

\section{Procedimentos Metodológicos}

Este estudo teórico-empírico, busca aplicação prática a partir de dados e informações teóricas (SILVA, 2014), cujo objetivo é o de apresentar o status da disponibilização e do compartilhamento de informações sobre serviços públicos no Brasil, alinhado com a legislação vigente sobre Governo Digital. Adota a natureza qualitativa e fontes secundárias, pois busca compreender, com base em dados qualificáveis, o atual estágio de compartilhamento de informações sobre serviços públicos entre entes federados no Brasil, ou seja, a realidade de determinados fenômenos, a partir da percepção dos diversos atores sociais.

A pesquisa utiliza-se da técnica de análise documental, para analisar dados constantes em documentos públicos, como o Portal Gov.br e sua documentação técnica; a base de dados do Índice ABEPTIC de Oferta de Serviços Públicos Digitais - IOSPD (ABEP-TIC, 2021), a qual identifica quais estados brasileiros atendem aos critérios relacionados ao provimento de informações sobre serviços públicos via internet; e a base de dados do Diagnóstico dos Portais de Serviços ao Cidadão dos Governos Estaduais e Distrital (GTD, 2021). 
Quanto aos procedimentos foram efetuados a: Identificação dos mecanismos de interoperabilidade para incorporação de informações externas sobre serviços públicos para o Portal gov.br; status da oferta de serviços federais e estaduais no Portal.gov.br; condicionantes para a oferta de informações sobre serviços públicos nos portais de serviços estaduais; Análise dos portais estaduais de serviços públicos que disponibilizam informações no gov.br e; Identificação dos componentes mínimos para a Base Nacional de Serviços Públicos.

O presente estudo analisou a oferta de serviços públicos na internet no nível federal e estadual. A oferta de serviços na esfera municipal não foi analisada por não haver municípios que compartilhem informações sobre seus serviços públicos no Portal gov.br. Além do Governo Federal, foram analisados os oito estados que, até a data da coleta de dados, compartilhavam tais informações com o Portal gov.br: Alagoas (AL), Bahia (BA), Distrito Federal (DF), Goiás (GO), Minas Gerais (MG), Paraná (PR), Rio Grande do Sul (RS) e Santa Catarina (SC).

\section{Análise e Resultados}

Uma parcela relevante dos desafios a serem superados pelos governos estaduais no âmbito do Governo Digital está disponível nos resultados do IOSPD (ABEP-TIC, 2020 e 2021). De acordo com a base de dados e a metodologia do Índice, que avalia critérios voltados a (1) Capacidades para a Oferta Digital de Serviços Públicos; (2) Oferta de Serviços Públicos por meios digitais e (3) Regulamentação sobre modernização para a Oferta de Serviços Públicos; os governos estaduais evoluíram em média, 9,69 pontos quanto a sua maturidade de oferta de serviços digitais, alcançando 57,31 (de 0 a 100), classificado como nível bom de maturidade. Todavia, na análise regional, o Norte, Centro-Oeste e cinco dos nove estados do Nordeste estão classificados em nível regular de maturidade, enquanto o Sul está no nível muito bom, com destaque para o RS, único governo que atingiu o patamar ótimo (ABEP-TIC, 2021).

Para compreender os avanços e desafios desta oferta de serviços públicos digitais, analisaremos o status da oferta federal e dos estados brasileiros nas subseções a seguir.

\subsection{Status da oferta de serviços federais e estaduais no Portal.gov.br}

A atual oferta de serviços públicos federais está majoritariamente concentrada no Portal gov.br, cuja coordenação é desenvolvida pela Secretaria de Governo Digital vinculada ao Ministério da Economia. O Decreto 9.756/2019 (BRASIL, 2019), instituiu o portal único "gov.br" e dispondo sobre as regras de unificação dos canais digitais do Governo federal. Anteriormente ao Portal gov.br, o governo federal desenvolveu ações prévias de caráter estruturante para a sua oferta de serviços públicos, como a regulamentação das Cartas de Serviços ao Usuário, do CDU, o desenvolvimento do Portal de Serviços do Governo Federal e a Plataforma de Cidadania Digital, instituída pelo Decreto Federal 8.936/2016 que estabelece as diretrizes e regras para a oferta de serviços públicos no âmbito dos órgãos e das entidades da administração pública federal direta, autárquica e fundacional (BRASIL, 2016).

Ao consolidar a oferta federal de serviços públicos, o Portal gov.br desempenha a função de Quadro Geral de Serviços Públicos do Governo Federal, conforme o Art. $3^{\circ}$ do CDU. Em julho/2021, havia 4.591 serviços federais no Portal gov.br, disponibilizados por 198 instituições federais (BRASIL, 2021d). Desta oferta de serviços, 3.235 serviços são classificados como totalmente digitais $(70,4 \%), 642$ serviços são 
parcialmente digitais (14,0\%) e 718 serviços são apresentados como não digitais $(15,6 \%)$.

O aprimoramento da oferta de serviços públicos é um desafio de todo o Estado brasileiro, e não apenas do Governo central. A proposição da BNSP é um importante passo para que haja uma visão ampla e sistêmica da atual oferta de serviços públicos nos três níveis da administração pública. Neste sentido, o Portal gov.br disponibiliza, através de mecanismos de interoperabilidade mencionados anteriormente, a indexação da oferta de serviços de oito entes federados estaduais (BRASIL, 2021e), onde em consulta realizada em julho/2021, conforme o Quadro 1, existem mais 12.053 serviços estaduais catalogados no Portal gov.br.

Quadro 1 - Serviços estaduais catalogados no Portal gov.br

\begin{tabular}{|c|c|}
\hline Unidade da Federação (UF) & $\begin{array}{c}\text { Informações sobre serviços } \\
\text { compartilhados com o gov.br }\end{array}$ \\
\hline $\mathrm{AL}$ & 4298 \\
\hline $\mathrm{BA}$ & 466 \\
\hline $\mathrm{DF}$ & 400 \\
\hline $\mathrm{GO}$ & 1320 \\
\hline $\mathrm{MG}$ & 1983 \\
\hline $\mathrm{PR}$ & 1197 \\
\hline $\mathrm{RS}$ & 1403 \\
\hline $\mathrm{SC}$ & 986 \\
\hline
\end{tabular}

Fonte: Os autores (2021).

\subsection{Mecanismos de interoperabilidade sobre serviços públicos no Portal gov.br}

Para a incorporação de informações sobre serviços públicos de outros entes federados no Portal Gov.br, foi estabelecido um modelo mínimo de dados (BRASIL, 2021f). A partir do modelo mínimo, os entes interessados devem disponibilizar uma interface de programação (API) gerando informações legíveis por máquina para que possam disponibilizar suas informações no Portal federal. O modelo mínimo é composto de título do serviço, nomes populares do serviço, descrição do serviço, hiperlink para a fonte original de informações sobre o serviço e, ente federado responsável pelo serviço.

A partir da disponibilização da API do ente federado, o Governo Federal pode adicionar a fonte de dados do ente federado para ser indexado pelo Portal Gov.br, conforme documentação disponibilizada pelo Governo Federal.

De acordo com a Figura 3, após a catalogação da API do ente subnacional, o Portal Gov.br passa a indexar os serviços subnacionais. Os serviços são indexados com as informações do modelo mínimo. Ao acessar um serviço subnacional, o usuário tem acesso ao hiperlink para o portal subnacional para ter acesso às informações com maior nível de detalhamento. 
Figura 3 - Modelo tecnológico de interoperabilidade e indexação de informações externas no Portal Gov.br

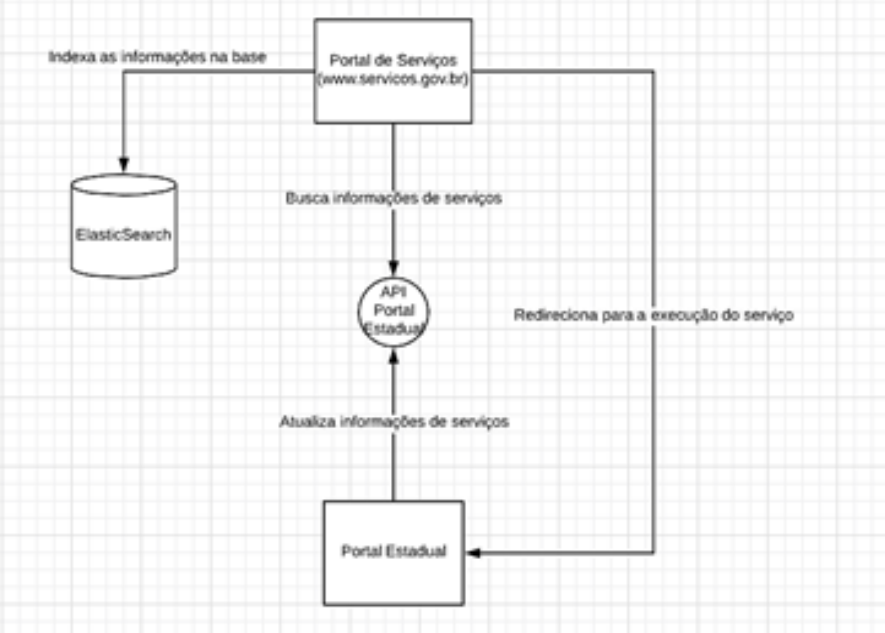

Fonte: BRASIL (2021e).

\subsection{Condicionantes para oferta de informações sobre serviços públicos nos PSCs}

Para identificar os condicionantes para a BNSP no âmbito dos estados, o IOSPD disponibiliza uma base de dados que permite verificar se os estados disponibilizam seus quadros gerais de serviços públicos na internet, bem como se regulamentaram a Lei 13.460/2017 que é responsável pela instituição dos Quadros gerais de serviços e respectivas Cartas de Serviços ao Usuário, sendo estas as fontes de informações primárias para a BNSP, conforme estabelecido nos Arts. 18 e 19 da Lei 14.129/2021. O Quadro 2 (parte hachurada em verde) sistematiza o status de disponibilização dos quadros gerais de serviços (e respectivamente das Cartas de Serviços ao Usuário) pelos governos estaduais, bem como se está integrado ao Portal gov.br.

Quadro 2 - Status dos Quadros Gerais de Serviços e das Cartas de Serviços ao Usuário.

\begin{tabular}{|c|c|c|c|c|c|c|c|}
\hline \multicolumn{5}{|c|}{ Disponibilização dos Quadros Gerais de Serviços } & \multicolumn{3}{|c|}{ Regulamentação das Cartas de Serviços ao Usuário } \\
\hline $\mathbf{U F}$ & $\begin{array}{c}1^{\text {a }} \text { Ed. } \\
2020\end{array}$ & $\begin{array}{c}2^{\mathrm{a}} \text { Ed. } \\
2021\end{array}$ & $\begin{array}{c}\text { Passou a } \\
\text { disponibilizar } \\
\text { entre as duas } \\
\text { edições? }\end{array}$ & $\begin{array}{c}\text { Disponibiliza } \\
\text { no portal } \\
\text { gov.br? }\end{array}$ & $\begin{array}{c}1^{\text {a }} \text { Ed. } \\
2020\end{array}$ & $2^{\text {a }}$ Ed. 2021 & $\begin{array}{c}\text { Regulamentou as Cartas de } \\
\text { Serviços entre as duas } \\
\text { edições do IOSPD }\end{array}$ \\
\hline $\mathrm{AC}$ & Não & Sim & Sim & Não & Não & Não & Não \\
\hline $\mathrm{AL}$ & Não & Sim & Sim & Sim & Não & Não & Não \\
\hline $\mathrm{AM}$ & $\mathrm{Sim}$ & Não & Não & Não & Não & $\mathrm{Sim}$ & Sim \\
\hline AP & Sim & Sim & Não & Não & Não & Não & Não \\
\hline BA & $\mathrm{Sim}$ & $\mathrm{Sim}$ & Não & $\mathrm{Sim}$ & $\mathrm{Sim}$ & $\mathrm{Sim}$ & Não \\
\hline $\mathrm{CE}$ & Sim & Sim & Não & Não & Não & Sim & Sim \\
\hline $\mathrm{DF}$ & $\mathrm{Sim}$ & Não & Não & Sim & Sim & Não & Não \\
\hline ES & $\mathrm{Sim}$ & $\mathrm{Sim}$ & Não & Não & Não & $\mathrm{Sim}$ & $\mathrm{Sim}$ \\
\hline GO & Sim & Sim & Não & Sim & Sim & Sim & Não \\
\hline MA & Não & Não & Não & Não & Não & Não & Não \\
\hline
\end{tabular}




\begin{tabular}{|c|c|c|c|c|c|c|c|}
\hline MG & $\mathrm{Sim}$ & Sim & Não & Sim & $\mathrm{Sim}$ & Sim & Não \\
\hline MS & Sim & Sim & Não & Não & $\mathrm{Sim}$ & Sim & Não \\
\hline MT & Não & Sim & Sim & Não & Não & Sim & $\mathrm{Sim}$ \\
\hline PA & Não & Sim & $\mathrm{Sim}$ & Não & Não & Não & Não \\
\hline PB & Sim & Sim & Não & Não & $\mathrm{Sim}$ & Sim & Não \\
\hline $\mathrm{PE}$ & Sim & Sim & Não & Não & Sim & Sim & Não \\
\hline PI & Não & Não & Não & Não & Não & Não & Não \\
\hline PR & $\mathrm{Sim}$ & Sim & Não & Sim & Não & Não & Não \\
\hline RJ & Não & Sim & $\mathrm{Sim}$ & Não & $\mathrm{Sim}$ & Sim & Não \\
\hline $\mathrm{RN}$ & Sim & Sim & Não & Não & Não & Não & Não \\
\hline RO & Não & Não & Não & Não & Não & Sim & Sim \\
\hline $\mathrm{RR}$ & Não & Não & Não & Não & Não & Não & Não \\
\hline $\mathrm{RS}$ & $\mathrm{Sim}$ & Sim & Não & Sim & $\mathrm{Sim}$ & Sim & Não \\
\hline $\mathrm{SC}$ & Sim & Sim & Não & Sim & Sim & Sim & Não \\
\hline $\mathrm{SE}$ & $\mathrm{Sim}$ & $\mathrm{Sim}$ & Não & Não & Não & Não & Não \\
\hline SP & Não & Sim & Sim & Não & Não & Não & Não \\
\hline TO & Sim & Sim & Não & Não & Sim & Sim & Não \\
\hline
\end{tabular}

Fonte: Os autores (2021), a partir de ABEP-TIC (2021).

No quadro, é possível observar que na $1^{\mathrm{a}}$ edição do IOSPD, em 2020, 16 governos estaduais informaram disponibilizar o Quadro Geral de Serviços nos seus portais. Na $2^{\mathrm{a}}$ edição, em 2021, houve uma evolução onde 21 governos estaduais informaram positivamente o atendimento a este critério. Observamos que no intervalo, 6 Governos passaram a disponibilizar o Quadro Geral e 1 deixou de fazê-lo. Ademais, o Quadro 2 (parte hachurada em azul) sistematiza o status de regulamentação do CDU quanto ao desenvolvimento das Cartas.

Observa-se que na $1^{\mathrm{a}}$ edição do IOSPD, 11 governos estaduais informaram ter regulamentado as Cartas de Serviços ao Usuário. Na $2^{\mathrm{a}}$ edição, também houve uma evolução onde quinze governos estaduais informaram positivamente o atendimento a este critério, onde neste intervalo quatro governos estaduais evoluíram nesta direção.

Para analisar como os governos estaduais estruturaram seus PSCs, Quadros gerais e Cartas de Serviços ao Usuário, em alinhamento com os requisitos necessários para a participação na BNSP, a pesquisa apresenta os casos dos oito governos estaduais que estão disponibilizando informações sobre serviços no Portal gov.br, a seguir.

\subsection{Análise dos PSCs que disponibilizam informações no gov.br}

O Governo de Alagoas mantém um PSC principal, disponível em www.alagoasdigital.al.gov.br e que faz a função de Quadro Geral de Serviços Públicos, mas os órgãos mantêm seus próprios portais. O Portal possui API pública, possibilitando a interoperabilidade com outros sistemas de informação, permitindo que Alagoas compartilhe informações sobre serviços com o gov.br, todavia sem consumir disponibilização de informações sobre serviços federais. A identificação única do gov.br é usada em algumas aplicações, mas a 
integração entre o PSC do Governo e a Rede gov.br ainda está em planejamento (GTD, 2021). Em julho/2021, o PSC informava disponibilizar 2.016 serviços (ALAGOAS, 2020). Destes, 141 serviços são classificados como digitais (7,0\%) e 1875 serviços são apresentados como demais serviços $(93,0 \%)$.

O Governo da Bahia mantém um PSC, denominado SAC Digital, que contém a oferta de serviços públicos digitais e não digitais, disponível no endereço www.sacdigital.ba.gov.br. Em julho/2021, o SAC Digital informava disponibilizar 701 serviços ofertados por 53 instituições (BAHIA, 2021). Deste total, 437 foram informados como digitais $(62,3 \%)$ e, por diferença, 264 serviços não se classificam como digitais $(27,7 \%)$. O Governo da Bahia não utiliza a solução de identificação única do gov.br. e a integração entre o PSC do Governo e a Rede gov.br ainda está em planejamento (GTD, 2021). Por outro lado, o Governo da Bahia possui também o portal Guia de Serviços, disponível em http://servicos.ba.gov.br (BAHIA, 2021b), que atua como Quadro Geral de Serviços Públicos, e que possui API pública, por onde o governo da BA compartilha informações sobre serviços com o gov.br, mas não realiza o consumo e disponibilização de informações sobre serviços federais.

Os serviços do Governo do Distrito Federal são disponibilizados no endereço www.df.gov.br (DISTRITO FEDERAL, 2021a), não havendo informações que identifiquem a quantidade de serviços ofertados nem sua classificação quanto à maturidade digital. Todavia, a integração dos serviços do DF com o gov.br ocorre através de um PSC da Secretaria de Economia do DF, disponível em www.receita.fazenda.df.gov.br, que aparentemente atua como Quadro Geral de Serviços e disponibiliza 438 serviços para cidadãos, empresários, outros contribuintes e governos e parceiros (DISTRITO FEDERAL, 2021b). O DF aderiu à Rede.gov.br e integrou seu PSC ao gov.br de forma unidirecional (BRASIL, 2021ce).

Goiás possui um PSC principal, disponível em www.goias.gov.br, mas os órgãos mantêm seus próprios portais. Desde maio/2021, Goiás lançou o "Expresso", integrado ao PSC principal, sendo uma nova plataforma estadual que oferece serviços da gestão pública por meio virtual e em terminais de autoatendimento (GOIÁS, 2021). O Expresso faz a função de Quadro Geral de Serviços Públicos, sendo através dele a integração de informações com o gov.br, todavia sem disponibilizar API pública dos serviços. O governo já realizou adesão à Rede gov.br (BRASIL, 2021c) desde 2019 e utiliza login único como o principal meio de autenticação do PSC. Também há integração do Portal com a Rede gov.br de forma bidirecional (GTD, 2021). Em julho/2021, o Expresso Goiás disponibilizava 701 serviços, (GOIÁS, 2021). Destes, 83 serviços são classificados como digitais $(11,9 \%)$ e, por diferença, 618 serviços não se classificam como digitais $(88,1 \%)$ (GOIÁS, 2021).

O PSC principal do Governo de Minas Gerais é o www.mg.gov.br, mas os órgãos mantêm seus próprios portais. (MINAS GERAIS, 2021). O PSC desempenha a função de Quadro Geral de Serviços Públicos, sendo através dele a integração de informações com o gov.br, todavia sem disponibilizar API pública dos serviços. Os serviços ofertados pelo governo de MG estão integrados e são disponibilizados no Portal gov.br. Os serviços do governo federal da mesma forma são disponibilizados no Portal mg.gov.br (GTD, 2021). Minas Gerais realizou a adesão à Rede.gov.br (BRASIL, 2021c).

Em julho/2021, através do Mapa de Transformação de Serviços do Programa Minas Atende, o Governo de MG informou disponibilizar 1051 serviços. Quanto à digitalização, MG avalia de forma distinta dos demais estados, mensurando não se os serviços são digitais, mas se as etapas destes serviços são ou não 
digitais. No período da coleta de dados, MG apresentou um Índice de Transformação Digital, que atingiu $72,83 \%$, de um total de uma meta estabelecida de $85,78 \%$ (MINAS GERAIS, 2021b).

O governo do Paraná possui um PSC principal, que oferta todos os serviços oferecidos pelo governo no endereço www.pia.pr.gov.br na plataforma identificada como PIA - Paraná Inteligência Artificial (GTD, 2021), porém os órgãos mantêm seus próprios portais. O PIA desempenha a função de Quadro Geral de Serviços Públicos, sendo através dele a integração de informações com o gov.br, todavia sem disponibilizar API pública dos serviços. Os serviços do governo federal da mesma forma são disponibilizados no PIA. Em julho de 2021, do total 5.262 serviços disponibilizados no PSC, 4.580 eram do gov.br, 23 de governos municipais e 649 serviços do próprio governo estadual (PARANÁ, 2021). O PIA possui uma identificação única do cidadão devolvida pelo próprio governo, ou seja, não utiliza o login único do gov.br, entretanto o Paraná realizou a adesão à Rede.gov.br (BRASIL, 2021c).

O PSC do Governo Rio Grande do Sul é o rs.gov.br (GTD, 2021), porém os órgãos mantêm seus próprios portais. Este PSC desempenha a função de Quadro Geral de Serviços Públicos, sendo através dele a integração de informações com o gov.br, sem disponibilizar API pública dos serviços. Os serviços do governo federal da mesma forma são disponibilizados no Portal rs.gov.br (GTD, 2021). O rs.gov.br utiliza a solução de identificação única do gov.br, tendo feito a adesão à Rede.gov.br (BRASIL, 2021c). Em julho/2021, dos 484 serviços públicos do governo gaúcho, $61 \%$ foram informados como digitais (RIO GRANDE DO SUL, 2021), sendo aproximadamente 295 serviços digitais. Por diferença, existem aproximadamente 189 serviços que não são classificados como digitais (39\%).

O governo de Santa Catarina também possui um Portal de Serviço ao Cidadão (PSC) principal, acessível por www.sc.gov.br, porém os órgãos mantêm seus próprios portais (GTD, 2021). Este PSC atua como Quadro Geral de Serviços Públicos, sendo através dele a integração de informações com o gov.br, todavia sem disponibilizar API pública dos serviços. O caminho inverso é verdadeiro, ou seja, os serviços do governo federal da mesma forma são disponibilizados no Portal sc.gov.br (GTD, 2021). O sc.gov.br utiliza a solução de identificação única do gov.br (SANTA CATARINA, 2021), tendo feito a adesão à Rede.gov.br (BRASIL, 2021c). Em julho/2021, do total 486 serviços disponibilizados no sc.gov.br, ofertados por 40 instituições, 180 serviços (37\%) são oferecidos de forma totalmente digital. Por diferença, existem aproximadamente 306 serviços que não são classificados como digitais (63\%).

O Quadro 3 resume as principais informações quanto aos PSC dos oito governos estaduais, bem como as formas de integração com a Rede gov.br.

Quadro 3 - Resumo das formas de integração das UFs com a Rede gov.br.

\begin{tabular}{|c|c|c|c|c|}
\hline UF & $\begin{array}{c}\text { Aderiu a Rede } \\
\text { gov.br? }\end{array}$ & $\begin{array}{c}\text { Há integração } \\
\text { bidirecional entre o } \\
\text { PSC e o gov.br? }\end{array}$ & $\begin{array}{c}\text { Utiliza identificação } \\
\text { única do gov.br? }\end{array}$ & $\begin{array}{c}\text { Disponibiliza API } \\
\text { pública de serviços } \\
\text { públicos }\end{array}$ \\
\hline AL & NÃO & NÃO & SIM & SIM \\
\hline BA & NÃO & SIM & SIM & SIM \\
\hline DF & SIM & SIM & SIM & NÃO \\
\hline GO & SIM & SIM & SIM & NÃO \\
\hline
\end{tabular}




\begin{tabular}{|c|c|c|c|c|}
\hline MG & SIM & SIM & SIM & NÃO \\
\hline PR & SIM & SIM & NÃO & NÃO \\
\hline RS & SIM & SIM & SIM & NÃO \\
\hline SC & SIM & SIM & SIM & NÃO \\
\hline
\end{tabular}

Fonte: Os autores (2021), a partir de GTD (2021) e BRASIL (2021c).

Observamos que Alagoas e Bahia são os únicos estados que não havia aderido à Rede gov.br. Por outro lado, Alagoas é o único dos oito estados que ainda não apresenta integração bidirecional com o portal do governo federal. Ainda, o estado do Paraná é o único que não utiliza a identificação única do gov br.

Quanto a requisitos de interoperabilidade, Alagoas e Bahia destacam-se por disponibilizar sua API de serviços de forma pública, possibilitando que as informações sobre serviços possam ser consumidas por qualquer sistema computacional, não apenas os governamentais, mas também por outros segmentos da sociedade.

\subsection{Funcionalidades e Serviços mais ofertados pelos Estados}

A pesquisa identificou as principais funcionalidades disponíveis nas oito unidades federativas que compartilham informações sobre serviços no portal gov.br (GTD, 2021). Não foram obtidas respostas dos representantes do Distrito Federal. Dentre as principais funcionalidades em PSCs, foram selecionadas as 26 mais comuns.

Figura 3 - Estágio de desenvolvimento das funcionalidades nos PSC.

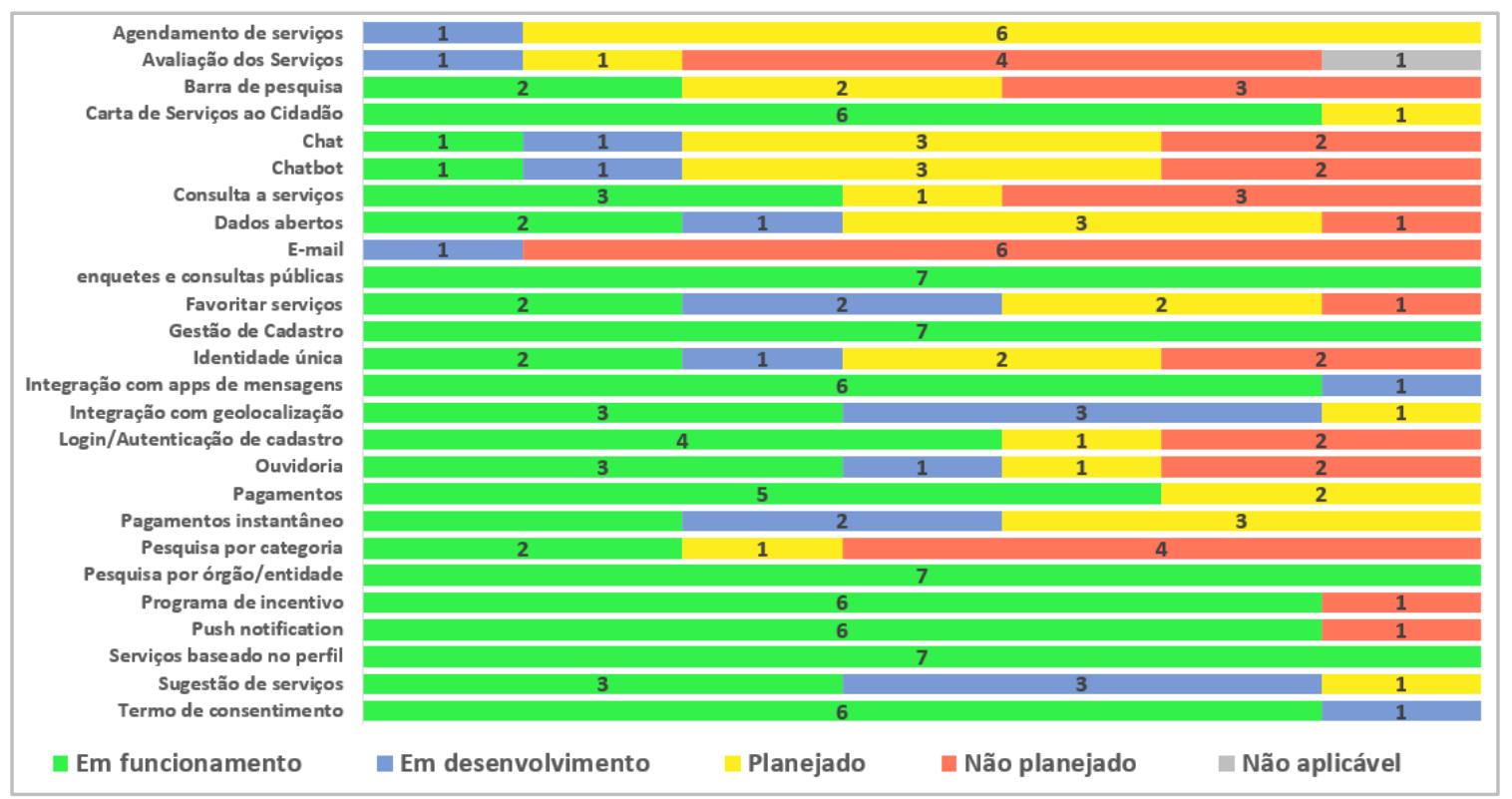

Fonte: Os autores (2021), com base em GTD (2021).

Conforme a Figura 3, foram utilizados os seguintes parâmetros para determinar seu estágio de implantação: a) Em funcionamento: funcionalidade se encontra operando atualmente no PSC; b) em desenvolvimento: funcionalidade está sendo desenvolvida, mas ainda não foi implementada para uso do cidadão no PSC; c) planejado: entende-se que a funcionalidade está vislumbrada para começar a ser desenvolvida no curto prazo; d) não planejado: funcionalidade não foi cogitada para implementação no curto 
e médio prazo.

Observamos que 11 das 26 funcionalidades analisadas estão predominantemente em funcionamento, representando $42 \%$ das funcionalidades observadas, indicando que os governos precisam avançar na disponibilidade de recursos em seus portais. Dentre as 11 funcionalidades em desenvolvimento, quatro estão operando em todos os PSCs contemplados, sendo elas: barra de pesquisa, carta de serviços ao cidadão, login/autenticação de cadastro e ouvidoria.

As funcionalidades de avaliação de serviços e gestão de cadastro são as que mais estão em desenvolvimento dentre todas as funções observadas pelas seis unidades federativas. Ainda, outras cinco funcionalidades estão predominantemente planejadas para serem desenvolvidas no curto prazo. São elas: chatbot, integração com aplicativos de mensagens (WhatsApp, Telegram etc.), notificações push, serviços baseados no perfil do usuário e sugestão de serviços no PSC.

Por fim, quatro funções estão distantes do horizonte de planejamento dos governos estaduais no curto e médio prazo, dentre eles as funcionalidades de chat, pagamentos na própria interface do portal, enquetes e consultas públicas e programas de incentivo.

$\mathrm{Na}$ sequência, foram analisados os principais serviços ofertados de forma digital pelos governos estaduais em seus PSCs. Foram listados 20 dentre os principais serviços comumente oferecidos em portais. Nesta análise, não foi identificado respostas do governo do Distrito Federal. Os resultados podem ser conferidos na Figura 4.

Figura 4 - Serviços oferecidos nos PSCs dos governos estaduais.

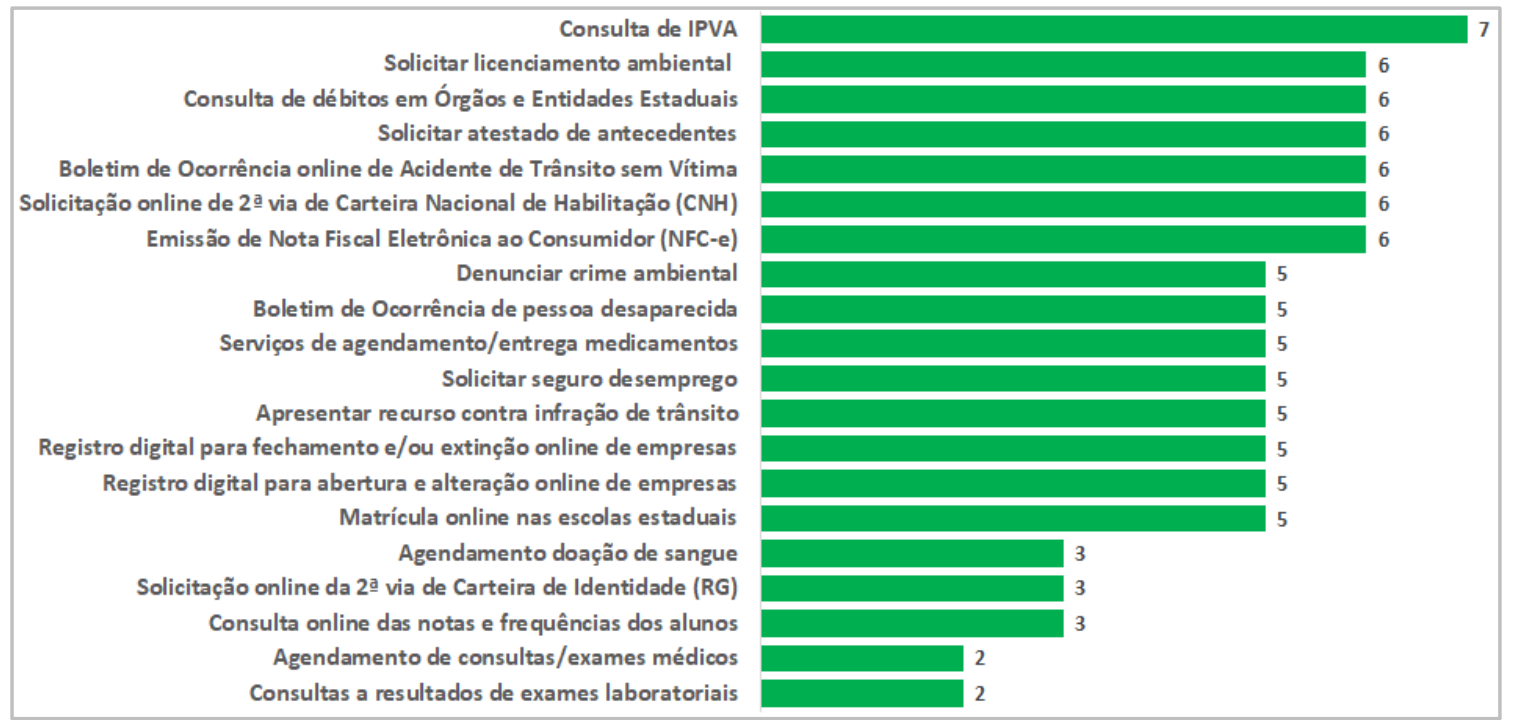

Fonte: Os autores, com base em GTD (2021).

Dentre os serviços analisados, $75 \%$ estão predominantemente presentes nos PSCs, o que indica uma alta taxa de adesão aos serviços digitais observados. Destes, o único serviço ofertado por todos os governos estaduais foi o de consulta do Imposto sobre a Propriedade de Veículos Automotores (IPVA). Os outros cinco serviços estão presentes em menos da metade dos governos estaduais, dentre eles, destaca-se o serviço de consulta a exames laboratoriais, presente em apenas dois estados, sendo este um serviço que durante a pandemia de COVID-19 poderia ter sido utilizado de forma mais conveniente pelos cidadãos para evitar 
deslocamentos.

\subsection{Componentes mínimos para a estruturação da Base Nacional de Serviços Públicos}

Em analogia com as características para IDs (RAJABIFARD et al., 2000; NAKAMURA, 2010; MARANHÃO, 2013), identificamos respostas para tais características a partir dos dados e informações analisados, conforme apresentados no Quadro 4. Nesse sentido, a BNSP pode ser analisada como um ambiente inicial para uma futura ID sobre Serviços Públicos do Brasil.

Quadro 4 - Características da BNSP a partir de Rajabifard et al., 2000; Nakamura, 2010; Maranhão, 2013.

\begin{tabular}{|c|c|}
\hline Características & Base Nacional de Serviços Públicos \\
\hline Hierarquia & Nacional \\
\hline $\begin{array}{c}\text { Conjuntos de dados } \\
\text { fundamentais }\end{array}$ & \begin{tabular}{c} 
Informações sobre serviços públicos disponibilizados no Portal Gov.br e nos PSCs estaduais \\
\hline Normas
\end{tabular} \\
\hline Redes & Leis federais 12.527/2011, 13.460/2017, 14.129/2021 e normativos estaduais \\
\hline Pessoas ou atores & Rede.gov.br e GTD.GOV (para colaboração); \\
\hline Coordenação & Governos federal e estaduais \\
\hline $\begin{array}{c}\text { Fatores de influências } \\
\text { externas }\end{array}$ & Qualidade das informações sobre serviços; disponibilidade institucional dos entes \\
\end{tabular}

Fonte: Os autores.

Complementarmente, a pesquisa identificou um fluxo de atividades para a Base Nacional de Serviços Públicos - BNSP, conforme identificado na Figura 5.

Figura 5 - Fluxo de atividades para a Base Nacional de Serviços Públicos
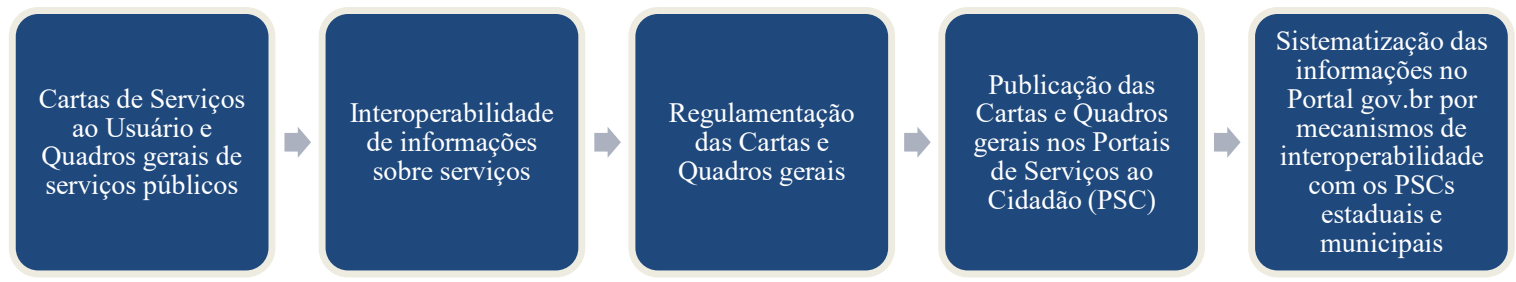

Fonte: Os autores.

\section{Considerações finais}

O presente artigo sistematizou o status da oferta de informações sobre serviços públicos no Brasil nos portais estaduais e federal, analisando dados secundários, especialmente sobre o Índice ABEP-TIC de Oferta de Serviços Públicos Digitais - IOSPD (ABEP-TIC, 2021), o Diagnóstico dos Portais de Serviços ao Cidadão dos Governos Estaduais e Distrital (GTD, 2021); e a oferta de serviços federais e estaduais no Portal gov.br.

Além da visão sistêmica da oferta de informações sobre serviços públicos no Brasil, o fluxo de atividades identificado é uma contribuição adequada para o desenvolvimento e consolidação desta Base, considerando que apesar da mesma ter sido instituída recentemente pela LGD, não houve detalhamento na lei 
sobre o seu funcionamento. Neste sentido, a pesquisa apresenta um fluxo lógico apresentado na Figura 5, auxiliando a definição de papéis e responsabilidades no âmbito federativo brasileiro para o desenvolvimento da BNSP.

As instituições, gestores e técnicos do setor público e a população em geral podem se beneficiar com a BNSP para fins como: (1) análise comparativa do fluxo de entrega de serviços públicos similares entre vários entes federados; (2) obtenção de insumos para o redesenho e otimização destes fluxos; (3) atuação integrada para simplificar a linguagem adotada nas Cartas de Serviços ao Usuário, facilitando o acesso da população aos serviços públicos; e (4) articulação de ações comuns entre vários entes federados para o desenvolvimento de soluções e métodos para otimizar e simplificar serviços que sejam comuns para estes entes.

Por fim, foi avaliado que a LGD inovou e trouxe contribuição muito relevante para o Governo Digital brasileiro ao propor a BNSP. Dialogando com Filgueiras, Flávio e Pallotti (2019), se as Cartas de Serviços ao Usuário iniciaram a transição do governo eletrônico para um governo digital, a BNSP tem potencial de acelerar essa transição à toda administração pública brasileira. Cenário possível, especialmente se houver uma coordenação nacional adequada, contemplando-a na Estratégia Nacional de Governo Digital para que seja um objetivo comum do Governo Digital do Brasil.

Sobre as futuras pesquisas, o presente artigo não analisou o conteúdo nem a qualidade das informações apresentadas pelos entes federados analisados, também não aprofundou a divergência da quantidade de serviços disponibilizados, seja nos Quadros Gerais de Serviços estaduais ou nas informações dos serviços estaduais indexadas pelo Portal gov.br. Porém, ainda não foi explorado as possibilidades de melhoria dos serviços públicos identificados no estudo, bem como análise temática sobre essa oferta de serviços (educação, saúde, fazenda etc.). Por fim, não houve uma análise crítica sobre os desafios e requisitos de interoperabilidade para consumo dessas informações pelas plataformas de serviços públicos.

Logo, estudos futuros podem se basear nestas limitações da pesquisa, bem como nos seus resultados, especialmente os componentes para a BNSP para evoluir a investigação e a proposição de caminhos para a estruturação e consolidação da BNSP.

\section{Referências}

ABEP-TIC. (2021). Índice ABEP-TIC de Oferta de Serviços Públicos Digitais. Associação Brasileira das Entidades Estaduais de Tecnologia da Informação e da Comunicação. Brasília. Recuperado de:< https://www.jornaldaabep.com.br/indice-de-oferta-de-servicos>. Acesso em: 21 jun. 2021.

Alagoas. (2018). Uma Proposta de Modelo de Integração e Compartilhamento de Informações para a Base

Nacional sobre Serviços Públicos do Brasil. Maceió, Governo do Estado de Alagoas. Recuperado de: https://tinyurl.com/bnspbr. Acesso em 23. jul. 2021.

(2020). Alagoas Digital. Maceió, Governo do Estado de Alagoas. Recuperado de: https://alagoasdigital.al.gov.br. Acesso em: 23 jul. 2021 
Araújo, G. R; Ávila, T. J. T.; Lanza, B. B. B. Impacts of an articulation group for the development of the Digital Government in the Brazilian Subnational Government. In DG. O' 21: The 22nd Annual International Conference on Digital Government Research, 21., 2021, online. Anais ACM, New York, NY, USA, p. 339-350.

Ariza, F. J. (2002). Calidad em La producción cartográfica . Espanha, editora: RaMa. 389p

Bahia. (2021). Sac Digital. Salvador, Governo do Estado da Bahia. Recuperado de: https://sacdigital.ba.gov.br. Acesso em: 23 jul. 2021

. (2021). Guia de Serviços - Serviços públicos prestados pelo Governo do Estado da Bahia. Salvador, Governo do Estado da Bahia. Recuperado de: http://servicos.ba.gov.br/. Acesso em: 23 jul. 2021

Banco Mundial. (2016). Relatório sobre o desenvolvimento mundial de 2016: dividendos digitais visão geral. Washington: Banco Mundial, 2016. 58 p.

Batista, A. H; Silva, N. B.; Miranda, C. M. C. (2013). Infraestrutura Nacional de Dados Abertos. In: Anais do VI Congresso CONSAD de Gestão Pública. Brasília, Distrito Federal, Brasil. Recuperado de: http://consad.org.br/wp-content/uploads/2013/05/093-INFRAESTRUTURA-NACIONAL-DE-DADOSABERTOS.pdf. Acesso em: 02. dez. 2021

Bizer, C.; Heath, T.; Berners-Lee, T. Linked Data - The Story So Far. Special Issue on Linked Data, International Journal on Semantic Web and Information Systems (IJSWIS), 2009. 22.

Brasil. (2008). Decreto $\mathbf{n}^{\mathbf{0}}$ 6.666, de 27 de novembro de 2008. Institui, no âmbito do Poder Executivo federal, a Infra-Estrutura Nacional de Dados Espaciais - INDE, e dá outras providências.. Diário Oficial da União: seção 1, Brasília, DF, p. 57, 28 nov. 2008.

. (2009). Decreto no $\mathbf{6 . 9 3 2}$, de 11 de agosto de 2009. Dispõe sobre a simplificação do atendimento público prestado ao cidadão, ratifica a dispensa do reconhecimento de firma em documentos produzidos no Brasil, institui a Carta de Serviços ao Cidadão e dá outras providências. Diário Oficial da União: seção 1, Brasília, DF, n. 153, p. 5, 12 ago. 2009.

. (2011). Lei $\mathbf{n}^{\mathbf{0}} \mathbf{1 2 . 5 2 7}$, de 18 de novembro de 2011. Regula o acesso a informações previsto no inciso XXXIII do art. $5^{\circ}$, no inciso II do $\S 3^{\circ}$ do art. 37 e no $\S 2^{\circ}$ do art. 216 da Constituição Federal; altera a Lei $n^{\circ}$ 8.112, de 11 de dezembro de 1990; revoga a Lei ${ }^{\circ} 11.111$, de 5 de maio de 2005, e dispositivos da Lei $\mathrm{n}^{\circ}$ 8.159, de 8 de janeiro de 1991; e dá outras providências. In: Diário Oficial da União: Edição Extra. Brasília, DF, 18 nov. 2011.

. (2015). Informações Básicas. Recuperado de:<https://www.gov.br/pt-br/guia-de-edicao-de-servicos-dogov.br/informacoes-basicas>. Acessado em 17 jan. 2021.

.(2016). Decreto n ${ }^{\mathbf{0}}$ 8.936, de 19 de dezembro de 2016. Institui a Plataforma de Cidadania Digital e dispõe sobre a oferta dos serviços públicos digitais, no âmbito dos órgãos e das entidades da administração pública federal direta, autárquica e fundacional. Diário Oficial da União: seção 1, Brasília, DF, n. 243, p. 7, 20 dez. 2016. 
.(2017). Lei no $\mathbf{1 3 . 4 6 0}$, de 26 de junho de 2017. Dispõe sobre participação, proteção e defesa dos direitos do usuário dos serviços públicos da administração pública. Diário Oficial da União: seção 1, Brasília, DF, n. 121, p. 4-5, 27 jun. 2017.

. (2019). Decreto $\mathbf{n}^{\mathbf{0}} \mathbf{9 . 7 5 6}$, de 11 de abril de 2019. Institui o portal único "gov.br" e dispõe sobre as regras de unificação dos canais digitais do Governo federal. Diário Oficial da União: seção 1, Brasília, DF, n. 70A, p. 3, 11 abr. 2019.

.(2021a). Lei $\mathbf{n}^{\mathbf{0}}$ 14.129, de 29 de março de 2021. Dispõe sobre princípios, regras e instrumentos para o Governo Digital e para o aumento da eficiência pública e altera a Lei $\mathrm{n}^{\circ} 7.116$, de 29 de agosto de 1983, a Lei $n^{\circ}$ 12.527, de 18 de novembro de 2011 (Lei de Acesso à Informação), a Lei no 12.682 , de 9 de julho de 2012, e a Lei n ${ }^{\circ}$ 13.460, de 26 de junho de 2017. Diário Oficial da União: seção 1, Brasília, DF, n. 60, p. 3 7, 30 mar. 2021.

.(2021b) Governo do Brasil. Gov.br alcança a marca de 100 milhões de usuários cadastrados. Brasília. Recuperado de: https://www.gov.br/sudeco/pt-br/assuntos/noticias/2021/gov-br-alcanca-a-marca-de-100milhoes-de-usuarios-cadastrados. Acesso em: 10. jul. 2021

(2021c). Governo do Brasil. Adesões à Rede Nacional de Governo Digital. Brasília, Recuperado de:< https://www.gov.br/governodigital/pt-br/transformacao-digital/adesoes-a-rede-nacional-de-governodigital>. Acesso em: 24. jul. 2021.

. (2021d). Governo do Brasil. Painel de monitoramento de serviços federais. Brasília, Recuperado de:< https://painelservicos.servicos.gov.br/>. Acesso em: 23. jul. 2021

(2021e). Governo do Brasil. Serviços Estaduais. Brasília. Recuperado de: $<$ https://www.gov.br/ptbr/servicos-estaduais>. Acesso em: 10. jul. 2021

(2021f). Rotina de Integração com Serviços Estaduais. Brasília. Recuperado de: https://servicosgovbr.github.io/portal-de-servicos/integracao/portais_estaduais_municipais.htm. Acesso em: 10. set. 2021

Camboim, S. P. (2013). Arquitetura para integração de dados interligados abertos à INDE-BR. $140 \mathrm{f}$. Tese (Doutorado) - Programa de Pós-Graduação em Ciências Geodésicas, Universidade Federal do Paraná, Curitiba.

Cavalcante, P.; Camões, M. (2017). Inovação pública no Brasil: uma visão geral de seus tipos, resultados e indutores. In: Cavalcante, P. et al. (Org.). Inovação no Setor Público: teoria, tendências e casos no Brasil. Brasília: Ipea. p.119-143.

Comissão Europeia. (2017) Digital4Development: mainstreaming digital technologies and services into EU Development Policy. Bruxelas: Comissão Europeia. 27 p.

Cunha, M. A.; Miranda, P. R. (2013) O uso de TIC pelos governos: uma proposta de agenda de pesquisa a partir da produção acadêmica e da prática nacional. Organizações \& Sociedade, v. 20, n. 66, p. 543-566,. 
Crespo González, J.; Criado, J. I. (2005). Evaluando el impacto de la implantación de la calidad en la Administraciones Públicas - Las Cartas de Servicios en la Comunidad de Madrid. Revista de Estudios de la Administración Local y Autonómica, núm. 298-299, pp. 269-295

Distrito Federal (2021). Governo do Distrito Federal. Brasília, Governo do Distrito Federal. Recuperado de: http://www.df.gov.br. Acesso em: 23 jul. 2021

. (2021). Portal de Serviços da Receita - Secretaria de Economia do Distrito Federal. Brasília, Governo do Distrito Federal. Recuperado de: https://www.receita.fazenda.df.gov.br . Acesso em: 23 jul. 2021

Filgueiras, F., Flávio, C. and Palotti, P. (2019). Digital Transformation and Public Service Delivery in Brazil. Latin American Policy, 10: 195-219.

Gil-Garcia, J. R. (2012) Towards a smart State? Inter-agency collaboration, information integration, and beyond. Information Polity, v. 17, n. 3-4, p. 269-280.

Gil-Garcia J. R.; Dawes, S. S.; Pardo, T. A. (2017). Essential aspect of innovation, co-production, transparency, and the generation of public value. Digital government and public management research: finding the crossroads.

Gonçalves, E. S. P.; Ricciardi, A. T. (2016). Plataforma de Serviços Públicos. In: Anais do IX Congresso CONSAD de Gestão Pública, 35 p. Brasília, Brasil. Acesso em: 29. mai. 2017

Goiás. (2021). Portal Expresso. Goiânia. Governo do Estado de Goiás. Recuperado de: https://www.go.gov.br Acesso em: 23 jul. 2021.

GTD. (2021). Grupo de Transformação Digital dos Estados e Distrito Federal. Diagnóstico dos Portais de Serviços ao Cidadão dos Governos Estaduais e Distrital. Recuperado de:https://gtdgov.org.br/uploads/publications/JuEKCUJIanOSnyf5WyGhJjESZx3OG0vZrzEoAh2M.pdf.A cesso em: 22 jul. 2021.

Gottschalk, P. (2008) Maturity levels for interoperability in digital government. Government Information Quarterly, v. 26, (1), 75-81.

Klievink, B; Janssen, M. (2009). Realizing joined-up government — Dynamic capabilities and stage models for Transformation. Government Information Quarterly, 26 (2) 275-284.

IBGE. Áreas Territoriais. 2018. Recuperado de: <https://www.ibge.gov.br/geociencias/organizacao-doterritorio/estrutura-territorial/15761-areas-dos municipios.html?edicao $=24050 \& \mathrm{t}=\mathrm{downloads}>$. Acesso em jan 17, 2021.

Estimativas da População. (2018b). Recuperado de: https://www.ibge.gov.br/estatisticas/sociais/populacao/9103-estimativas-depopulacao.html?edicao=22367\&t=resultados\%0A. Acesso em: 17 jan. 2021.

Lima L. A. T.(2012). Infraestrutura de dados espaciais como ferramenta de integração, disseminação e análise de dados para o Sistema Estatístico Nacional de Cabo Verde. Dissertação de Mestrado. (Mestrado em Ciências e Sistemas de Informação Geográfica) - Universidade de Cabo Verde, Cabo Verde. 110 f. 
Maciel, V. F; Piza, C. C. D. T; Penoff, R. N. (2009). Desigualdade regionais e bem-estar no Brasil: quão eficiente tem sido a atividade tributária dos estados para a sociedade. Planej. e Políticas Públicas, v. 33, p. 291-318.

Maranhão, V. C. (2013). Modelagem e Controle de Qualidade de uma Infraestrutura de Dados Espaciais para o Estado de Pernambuco. (Dissertação de mestrado). Programa de Pós-graduação em Ciências Geodésicas e Tecnologias da Geoinformação. Universidade de Pernambuco, Recife, Brasil. 160f.

Mezzaroba, M; De Almeida, T; Ulbricht, V. (2016). Acessibilidade em portais de Governo Eletrônico do Poder Judiciário. InfoDesign - Rev. Bras. Des. da Informação, v. 13, n. 1, p. 93-106.

Meyerhoff Nielsen, M.; Jordanoski, Z (2020). Digital transformation, governance and coordination models: A comparative study of Australia, Denmark and the Republic of Korea. In: DG. O '20: The 21st Annual International Conference on Digital Government Research, 21., 2020, online. Anais... online: Digital Government Society. p. 285-293.

Minas Gerais. Portal MG.GOV.BR. Recuperado de: <https://www.mg.gov.br>. Acesso em: 23 jul. 2021.

Minas Atende. Recuperado de: https://www.mg.gov.br/conteudo/atendimento/minas-atende. Acesso em: 23 jul. 2021.

Nakamura E. T. (2010) Infraestrutura de dados espaciais em Unidades de Conservação: uma proposta para disseminação da informação geográfica do Parque estadual de intervales. Dissertação (Mestrado em Geografia Física) - Universidade de São Paulo, São Paulo. 142 f.

Nebert, D.D. (2004) Developing Spatial Data Infrastructures: The SDI Cookbook, version 2.0. GSDI. Recuperado de: http://gsdi.org/docs2004/Cookbook/cookbookV2.0.pdf,

OCDE. (2014). OECD Science, Technology and Industry Outlook. "The use of digital technologies, as an integrated part of governments' modernisation strategies, to create public value". OECD Publishing, Paris. . (2018). Organização para a Cooperação e Desenvolvimento Econômico. Promovendo a Transformação Digital dos Países Africanos de Língua Oficial Portuguesa e Timor-Leste (PALOP-TL). Paris: OECD Publishing.

PARANÁ. Portal de Serviços do Governo do Paraná. Paraná Inteligência Artificial. Recuperado de: $<$ https://www.pia.pr.gov.br>. Acesso em: 22 jul. 2021.

Rajabifard, A; Williamson, I. P.; Holland, P.; Johnstone, G. (2000). From Local to Global SDI initiatives: a pyramid building blocks, In: Proceedings of the 4th Global Spatial Data Infrastructures Conferences, Cape Town, South Africa.

Rio Grande do Sul. Plataforma unificada de serviços do Governo do Estado do Rio Grande do Sul. Recuperado de: https://www.rs.gov.br. Acesso em: 22 jul. 2021.

Santa Catarina (2021). Plataforma unificada de serviços do Governo de Santa Catarina. Recuperado de https://www.sc.gov.br. Acesso em: 22 jul. 2021. 
Scholl, H.; Klischewski, R. (2007) E-government integration and interoperability: framing the research agenda. International Journal of Public Administration. Londres, n.8,(30), 889-920.

Silva, A. (2014). Metodologia de Pesquisa: Conceitos Gerais. Univ. Estadual Do Centro-Oeste Unicentro, p. 57.

Stoeckl, K.; Stoeckl, B. (2017). Qualidade de atendimento no serviço público: uma análise da divulgação e implantação da carta de serviços ao cidadão nas universidades federais. Práticas em Gestão Pública Universitária, 1(1), 102-121. Recuperado de: <https://revistas.ufrj.br/index.php/pgpu/article/view/3377>. Acesso em: 22. jul. 2021. 